\title{
Benefits Optimization through III-Informed Client Competency Acquisition and Engagement in Renovation Works Flow
}

\author{
Christy P. Gomez ${ }^{1}$ \\ Abdulazeez U. Raji2 \\ ${ }^{1}$ Assoc. Professor, Department of Construction Management, Universiti Tun Hussein Onn \\ Malaysia. 86400, Batu Pahat, Johor, Malaysia \\ ${ }^{2} P h D$ Student, Department of Real-estate and Facilities Management \\ Universiti Tun Hussein Onn Malaysia, abdulazeezraji@hotmail.com
}

\section{Doi:10.5901/mjss.2016.v7n5p335}

\section{Abstract}

\begin{abstract}
In Malaysia, landed residential building design for mass housing has been influenced by the orientation towards a "seller's market, without prioritizing the changing needs of the owner-occupant. This has contributed to the growing trend of having to "remodel" homes that is currently dominated by "low-value adding practices" that are embedded within traditional benefits realization principles, amounting to brief freezing. There is a disregard for client's engagement at the construction phase, wherein the client is constrained by the practice of restrictive benefits realizations. This issue is underlined by a predominant positivist orientation to the issue of client participation that does not recognize residential housing client's ability for competency acquisition in realigning requirements to maximize benefits. This paper proposes that value maximization for such a client can best be achieved through dynamic engagement with the renovation contractor to allow for value-driven 'disruptive innovation' practice during the construction phase. Focusing on requirements capture as a process rather than an output, it is proposed that client's requirements can be realigned to maximize benefits based on a dynamic benefits realization model. This issue of benefits maximization is viewed from a social science perspective of primary stakeholder engagement within a legitimate peripheral mode of participation acting from within a community of practice whilst operating in a relational contracting environment.
\end{abstract}

Keywords: Benefits realization, disruptive innovation, renovation works, relational contracting.

\section{Introduction}

In Malaysia, residential building design for landed mass housing has been influenced by the orientation towards a "seller's market; without prioritizing the changing needs of homeowners. These designs are done without any serious emphasis on future adaptability. It has led to the growing trend of having to "remodel" homes, wherein the practices are currently dominated by low-value adding practices. One such practice is the lack of consideration for client's ability to influence maximization of benefits at the construction phase of renovation works. This paper argues for an emphasis on high-value adding practices oriented towards optimizing clients benefits based on realigning requirements past the traditional post-design phase.

There is a tendency for mass terraced housing property owners (the major type of housing in Malaysia) of new property in Malaysia to undertake renovation works within a ten year period (see Raji and Gomez, 2014). In the process of undertaking renovations, additional requirements (changes) are included into the renovation works on commencement of construction. Viewed from mainstream positivist notions, these actions of active engagement at the construction phase by the client are viewed as being disruptive to existing workflow, ignoring the value enhancement component; viewing requirements capture from a singular lens. Following Rooke et al. (2010) customer value is conceived in terms of outcomes, the effects that the outputs have on the customer. Hence, relying on the Unique Adequacy (UA) Requirements of Methods (Garfinkel, 2002) to be applied by the client for determining value, the issue of intersubjectivity of 'value' is not problematic.

The residential property homeowners undertaking renovation works can be categorized primarily as "one-off", illinformed clients (IIC). They are further on referred to simply as ill-informed clients (IICS) who typically lack the adequate knowledge and skills (competency) to influence the architect and contractor at the outset (at the pre-construction phase) to implement alternative designs and changes to initial design. Their ability to maximize their benefits in terms spatial 
functionality is limited by their lack of knowledge and skills (competency) in exploratory scenario planning for benefits optimization. However, functioning in an active engagement mode with the renovation team, these IICs can develop the ability (competency acquisition in exploratory scenario planning) to contribute towards value maximization for their own ends. This is seen to be achieved primarily through acquiring increased competence to influence the realignment of requirements. Tillman, Tzortzopoulos and Formoso (2010) point out that stakeholder engagement is an important issue when considering a social science perspective to benefits realization. Hence, an interpretivist approach is taken in understanding current practice and theorizing on possibilities by critical reflection on primary experiential data as a participant-observer.

It is clear that modifications are primarily aimed at providing better quality of life for the homeowners and improve the functional aspect of the house. According to Omar et al. (2003) the solution of "one design fits all" does not accommodate individual's specific needs and subsequently the evolving changing needs of a household. It is noted by Boris et al. (2005) that homeowners modify for two major reasons; either to enhance property value or improve performance of utility to accommodate changing needs. Additionally, within the Malaysian context of renovation works on residential property it is clear that the IIC do not seem to have their requirements clearly defined from the start. Hence, the objective of this paper is to propose a Benefits Maximization Model for renovation works of mass housing in Malaysia that can allow IICs to maximize their benefits (the aim) by focusing on the process of requirements capture by embedding the opportunity for enhancement of requirements within the renovation process workflow. This is seen to be driven by competency acquisition by the IIC within the regime of practice of the renovation team. The epistemological basis for conceiving the potential for benefits maximization by the client during the construction phase is based on constructivist theorizing for generating value within Communities of Practice (CoPs) of the renovation project team, inclusive of the client. This is seen to take place within a relational contracting environment. Based on experiential data of the researchers, it is argued here that traditional renovation practice is restricted by four methodological constraints. In having addressed these constraints, the emphasis then needs to be refocused towards benefits realization through the requirements capture process rather than requirements capture as a task culminating in the traditional "client's brief". With reference to this context, the process of requirements capture is illustrated in Fig. 1 below, viewed from a simplified one-dimensional perspective.

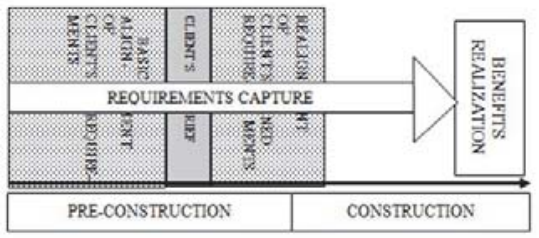

BENEFITS

MaXtMazation

Figure 1: One dimensional perspective of requirements capture process (Dynamic Benefits Realization Model - DBRM Part 1)

\section{Restrictive Benefits Optimization}

Traditionally the IICs have been constrained by non-constructivist framing of their role, placing emphasis on the contractor's perspective of achieving 'requirements capture' that is viewed as a deterministic output rather than a process. This perspective ignores the dynamics and multi-dimensionality of benefits realization from a client's perspective. Thus, disregarding the value potential of the IIC to engage with the 'renovation team community of practice'.

It is not surprising that Reifi and Emmit (2011) note that clients have been criticized for failing to appreciate that a change request during the design stage can potentially result in a complete redesign and elevate the complexity of the production process since they generally have no understanding in the commissioning process (note that the reference is to the design stage). Such stigmas have led to a cultural predisposition of negative client engagement that has contributed to restrictive benefits realization (RBR). This is exemplified by the traditional practice of requirements capture in terms of a task culminating in the client's brief prior to the construction phase. However, by placing emphasis on the requirements capture as a process, benefits realization is seen as being externalized from tasks and related to competency leading to benefits maximization.

The notion of RBR within small building works (renovation works) is influenced by the low emphasis on valuebased information and the lack of legitimacy accorded to client's involvement within the current requirements capture process. This paper proposes that value maximization, as benefits realization, for such a client can best be achieved 
through dynamic engagement in a relational sense with the renovation contractor to allow value-driven disruptive innovation on the part of the client to realize their potential benefits and realign requirements capture according to valuebased information as the work proceeds. However, based on experiential data derived from two participant-observation case studies, a ball park estimate for this to happen on any one renovation project is seen to be credibly viable within $80 \%$ of work progress for any one section of work. The scope of renovation works referred to in this paper, generally involves minimal structural work and minimal standardized work.

\section{Constraints to Benefits Optimization}

It is clear that when requirements are presented, they are rarely ready to be implemented; someone has to transform the brief into a different form of request, which can be analyzed and ultimately translated into a requirement (Wiegers, 2003; Kotonya and Sommerville, 1999). However, there can be various ways to put requirements into action that ultimately can have an influence on the value creation of the project (Lawrence, 1997; Kiviniemi, 2005).

It is noted by Sapountzis, Harris and Kagioglou(2008a) that the concept of benefits realization has been emerging in recent times as an important factor for successful programme, and additional areas of the construction process could leverage on the concept of benefits realization, including that of decision making and optioneering, performance management, impact assessment, value flow and generation, stakeholder requirements capture, change management and continuous improvement (Sapountzis, Harris and Kagioglou, 2008b).

It is noted by Garnett (1999) that, "a review of process theory and particularly, process theory in construction is [....] predominantly towards a positivist view where generic processes are sought ....." (p. 425). Additionally, in this respect, the emphasis in taking a positivist orientation, has been primarily to focus on objective outcomes in the form of 'artefacts', such as the client's brief, as a singular structured mode or mechanism for clearly identifying clients requirements; at the expense of other process based knowledge. This positivist perspective to sense-making disregards the 'growth' and 'learning' characteristic embedded within dynamic social processes such as realignment of requirements. This action of realignment of requirements is enabled by competence building capacity of the active IIC.

Additionally, even though there is evidence of research that does not limit the notion of the client's brief being cast in stone at the outset of the construction project (described earlier as mainstream practice), the issue of realigned requirements being injected into the construction phase is however not addressed. The process of refining requirements at the construction phase is often considered to be disruptive to design and work plan. This phenomena has been previously viewed within bounded rationality terms of being solely contributing to "increased costs" within the categorization of variation orders. However, this paper recognizes that in the case of renovation works, these realigned requirements tend to arise due to increased competency of IIC through engagement within an actor-network regime with existing renovation contract workers. This notion of competency as an analytical device is seen to extend existing boundaries of understanding in value maximization or benefits maximization for the client.

In terms of requirements capture, traditionally benefits realization is aimed at being secured by the client/user through the client's brief prior to the construction phase and not on a continuous basis; implying client/user participation being limited to the briefing process; a form of 'brief freezing'. Although more recent research (see, Barrett and Stanley, 1999; Blyth and Worthington, 2001; van der Voordt and van Wegen, 2005; and Jensen, 2006) has indicated that a continuous briefing process within the lifecycle of a project can yield better results, scant attention is placed on the IIC's issue of 'competency' and the ability to maximize client's benefits through their engagement within the community of practice (CoPs) of the renovation project team.

\section{Methodology}

We the researchers as human agents are seen to be engaged within the process of contributing theories to managers. In this particular instance, it is found that the practical application of the Theory of Constraints as a generative methodology for the formulation of actionable problem solving to improve processes for maximizing benefits for client's in renovation works is a valid theory to utilize. Hence, the approach has been to use the Goldratt's Theory of Constraints (TOC) to address the debilitating effect on the ability to maximize benefits for the client. The theory of constraints is a system approach based on the premise that there is at least one constraint (known as bottlenecks, delays, and barriers) in every organization that prevents the organization from utilizing its capability and capacity to achieve the organizational objectives (Goldratt, 1986). According to Goldratt (1986), the TOC approach focuses on the process of the ongoing improvement inclusive of effectively performing a series of 5 steps which are essentially involved in cause and effect thinking processes (see Figure 2). 


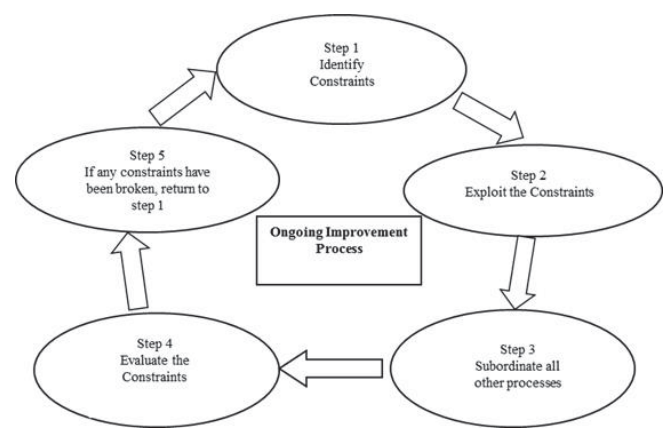

Figure 2: Five Steps of TOC Process (adapted from Goldratt, 1986)

Using Theory of Constraints (TOC) analysis alongside critical theory perspective, four basic deficiencies in renovation work practice is identified as Methodological Constraints to sense-making with regards to the issue of benefits maximization need to be addressed. They are:

- The predominant simplistic negative perception of 'variation orders' in design work that is considered to impact the project solely in terms of increased costs.

- The positivist framing of the IICS as an object devoid of innate abilities and dynamic characteristics that acts as a constraint, restricting their active engagement within the construction process.

- Disregard for taking into account the lean principle of allowing for 'design' decisions to be left to the last responsible moment right into the construction phase; thus reducing the ability to prioritize benefits maximization for the client.

- Bounded rationality perspective on client's involvement as contributing only in terms of disruptive workflow within the construction phase, limiting a broader application of value analysis.

This methodology is chosen based on the premise that the IICs by nature do not have their requirements well defined from the start, and thus there is the need to take into serious consideration the dynamic nature of the design process within the liberating principle of the TOC underlined in the form of the four methodological constraints as stated above. Hence, if designs are not considered to be static, then the design review of approved plans and designs for renovation should be considered as part of the process for benefits maximization; within the context of doing so at the last responsible moment. This lean principle of waste minimization and value maximization within the design process as forwarded by Tommelein, Rileyand Howell (1999)is fundamental to situating this paper. It is in this context that this form of transitional disruptive workflow is seen to be a high value adding practice, overriding the predominant notion negatively viewed solely as a form of workflow disruption. Hence, the original notion of disruption accorded to client's involvement is framed here as disruptive innovation, a notion popularized by Christensen (1997).

\section{Competency Acquisition by Client Towards Benefits Optimization}

Taking the analogical reasoning as to the significant impact of the contractor's involvement in design for enhancing buildability/constructability, similarly the client is best placed to figure out his requirements through exploratory scenario planning. Although being an ill-informed client requires a certain level of competence acquisition to be able to best communicate his interests and influence the realignment of requirements within the terms of benefits maximization.

Non-value adding activities and waste is generated through the design brief due to inadequacies in brief documents (communication) and brief freezing. The client in a construction project is considered as integral to the design process. However, it is argued that in residential renovation works practice the client is generally viewed as an illinformed client (IIC). The IIC is primarily operating only within a negatively perceived role as a disruptive element, hence there is no serious consideration given towards such a client's contribution that can result in benefits maximization. Traditionally, disruptive workflow is seen as a negative concept that is categorically ignored and hypothetically accorded the infamous non-value adding activity label. However, applying a basic principle of value for money (VfM), a client can decide to negotiate changes based on realignment of requirements to satisfy their need to maximize their benefits based on the lean principle of allowing for design decisions to be left to the last responsible moment. Taking the analytical perspective of "competency", the critical component that can enable the client to be acknowledged as "member to a practice', the client is able to engage with the renovation project team at a more participative level to maximize benefits 
during the construction phase (See Fig. 3), acting within a community of practice (CoP).

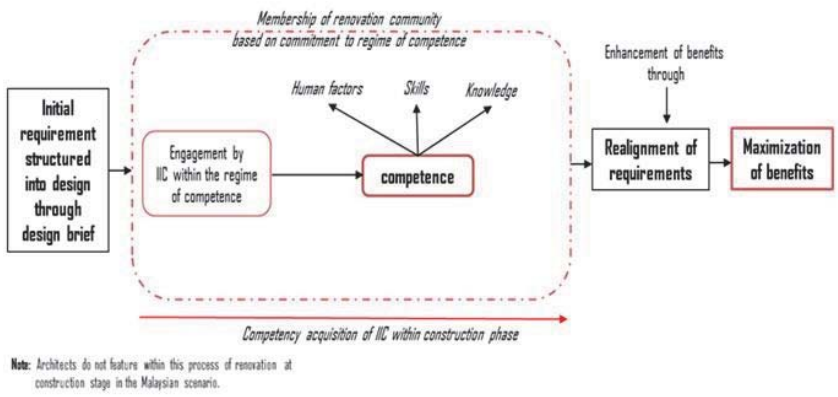

Figure 3: Competency acquisition of ICC within construction phase

\section{Community of Practice (CoPs)}

The term 'community of practice' was coined by Etienne Wenger and Jean Lave in the early 1990s to describe 'a group of people who share a concern, a set of problems or a passion about a topic, and who deepen their knowledge and expertise by interacting on an ongoing basis' (McDermott,Wengerand Snyder, 2002). CoPs are characterized by mutual learning, shared practice and joint exploration of ideas. They are distinct from other types of groups, such as project teams, working groups and social networks in that they are self-selecting, often voluntary and have fluid goals around learning rather than management objectives. They take on and spread new knowledge with a focus on implementation, rather than just theory, and can embrace an ongoing cycle of learning and doing. According to Hearn (2009) due to CoPs characterization by a community, a bound group of people, they can create trusted relationships for the exchange and practice of ideas. At their best, CoPs are naturally self-incentivizing. Members tend to stay involved and invest in CoPs due to the inherent rewards of social learning and collaboration. This also means that many CoPs emerge naturally from existing relationships and allegiances.

The notion employed here is that of Legitimate Peripheral Participation (LPP) as understood within the concept of Communities of Practice (CoP), wherein the client becomes engaged within the design considerations scenario and is seen as being accepted as a 'member' in terms of LPP engagement. It is through having achieved this legitimacy status that the client can then be part of the process that triggers innovative design inputs to enhance benefits maximization. This process is represented within the scope of three phases on the renovation lifecycle (see Fig. 4). In this research the focus is on benefits maximization in terms of functionality of space.

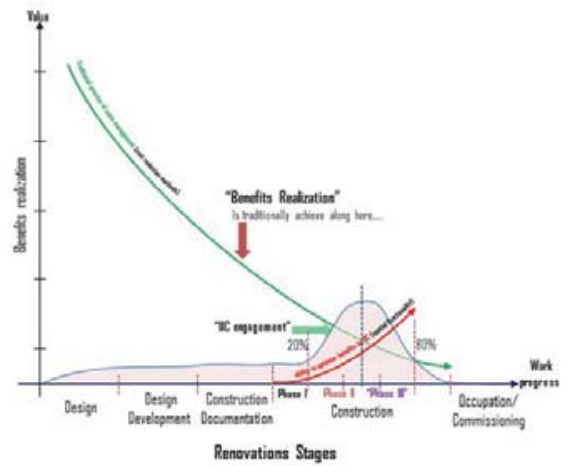

Figure 4: Benefits realization within renovation life cycle

\subsection{Phase I: Minimum client engagement}

At this phase of the housing renovation works, the "one-off" ill-inform client is involved in a minimum capacity of defining his requirements. The client at this stage employs the concept of ethnographic observation trying to understand the 
transformation process of design leading to specific outputs and the flow of the production process. At this stage the client lacks the ability to communicate and engage with the contractor towards optimizing his benefits, whilst involved in the requirements capture process.

\subsection{Phase II: Moderate client engagement}

At this stage of the housing renovations works, the "one-off" ill-informed client is moderately involved in the production by testing some basic knowledge (skills) through exploratory scenario planning, acquired during the observation phase. It is conceived that at this stage the client is within the mode of Legitimate Peripheral Participation (LPP), which is the culmination of the process of gaining acceptance as a member of the renovation project team (see Lave and Wenger, 1991). The level of participation varies according to the level of recognition of the Legitimacy of the client's Peripheral Participation as accorded by the contractor's team.

\subsection{Phase III: Active client engagement}

At this phase of the housing renovations works, the participatory "one-off" ICC client becomes better equipped with some technical skills and knowledge to be able to participate actively in the housing renovation workflow, realigning requirements capture to maximize benefits. This is a form of dynamic engagement by the ICC with the renovation contracting team to allow 'disruptive innovation', recognized within traditional workflow analysis as being disruptive. The level of participation is heightened to that of Focused Legitimate Peripheral Participation (FLPP), involving active engagement with the contractors' team (see Gomez, 2002). The ill-informed client is only then able to credibly engage in the renovations works process whilst operating within a relational contracting environment.

\section{Relational Project Delivery (RPD)}

Matthews and Howell (2005) note that maximizing value and minimizing waste at the project level is difficult when the contractual structure inhibits coordination, they proffer that the relational contracting approach is able to align project objectives with the interests of key participants. Relational project delivery methods (RPD) have been widely proffered as a solution to maximizing holistic project value creation. Aapaoja, Haapasalo and Söderström(2013) emphasized on early stakeholder involvement as one of the foundations of RPD. Within this context the ICCs active participation is realized for further value creation during the construction phase (see Fig. 5).

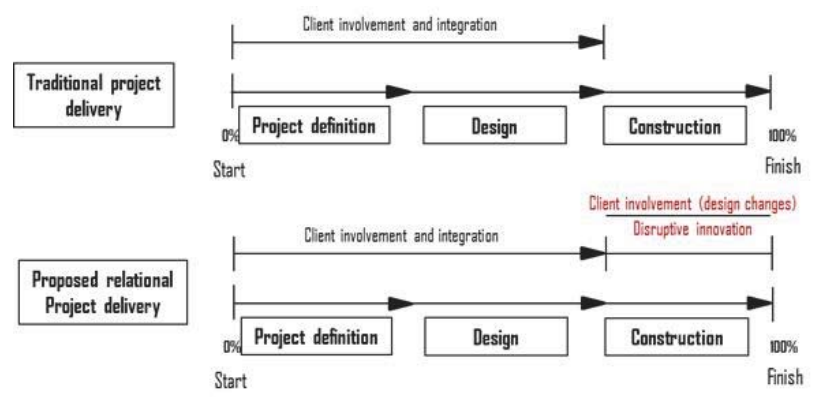

Figure 5: The difference between traditional and the proposed relational renovation projects delivery

The mainstream view is that the possibilities of influencing project success are seen to be best during the early project stages, because decisions made early reduces unnecessary changes during later development stages (Mottonen, et al., 2009). In this paper, the notion of success in renovation works is premised by benefits maximization realization (BMR) expressed in terms of value satisfaction experienced by client. This is achieved by the client participating without being confined by the traditional Four Methodological Constraints affecting renovation works. Figures 4 and 5 illustrate the scope between traditional renovation projects delivery and the proposed relational renovation projects delivery framework for benefits maximization. 


\section{Competency Conceptual Framework for Benefits OPTimization}

In using the analytical device of competency from a production science and social science perspective, a conceptual framework for benefits maximization is forwarded (see Fig. 6). Wherein, the human factor variables that come under the 'social engagement' category are attributes of competency from a social science perspective. Whilst the technical skills and technical knowledge that comes under the 'production' category are attributes of competency from a production science perspective.

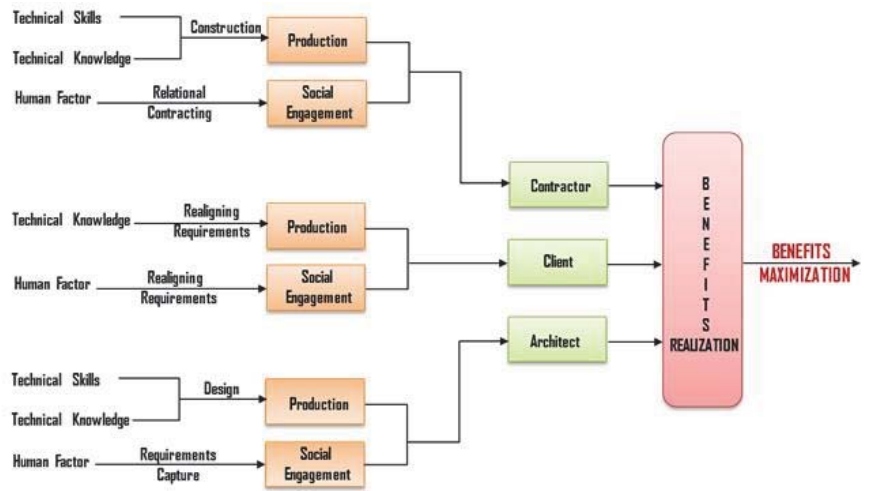

Figure 6: Competency conceptual framework for benefits optimization (Benefits Realization Model - BRM Part 2)

\section{Conclusion}

Renovation contractors currently are clearly not in the practice of allowing for benefits maximization during building renovation works process, as it is considered to be disruptive to their work flow. This notion of disruption is understood in the traditional sense of limiting changes and maintaining original work flow priority.

It is apparent that best value is not a common goal of the architect, contractor and client who are engaged in residential building renovation works. The design is done in a rather minimalistic manner, aimed at securing less problematic and commonly applied solutions from the perspective of the architect and contractor.

This paper proposes that value maximization for a "one-off", ill-informed renovation works client can best be achieved through dynamic engagement with the contracting team to allow disruptive innovation on the part of the client to realize benefits to be accrued and realign requirements capture through the proposed dynamic benefits realization model (see Fig. 1 and 6 as DBRM Part 1 and 2). Within this context, the client is seen to have the capacity to acquire competency to be actively engaged with the renovation project team in order to maximize benefits. The ill-informed client is only then able to credibly contribute to the renovation works process whilst operating within a relational contracting environment.

\section{Acknowledgement}

This research is financially supported by the Universiti Tun Hussein Onn Malaysia under the Office for Research, Innovation, Commercialization and Consultancy (ORRIC) fund. We will also like to acknowledge that part of this paper was presented at the $23^{\text {rd }}$ Annual Conference of the International Group for Lean Construction in Perth, Australia, 2015.

\section{References}

Aapaoja, A., Haapasalo, H., \& Söderström, P. (2013). Early Stakeholder Involvement in the Project Definition Phase.Case Renovation. ISRN Industrial Engineering, pp.1-14.

Barrett, P.S. \& Stanley, C. (1999). Better Construction Briefing. Oxford: Blackwell Science.

Blyth, A. \& Worthington, J. (2001). Managing the Brief for Better Design. London and New York: Spon Press.

Christensen, C. M. (1997). The Innovator's Dilemma. Cambridge, Massachusetts: Harvard Business School Press.

Garfinkel, H. (2002). Ethnomethodology's Program: Working out Durkheim's Aphorism. Lanham: Rowman \& Littleford.

Garnett, N. A. (1999). Developing lean thinking in construction: a naturalistic enquiry. In:Proceedings of the 7th Annual Conference of the 
International Group for Lean Construction. University of California, Berkeley, 26-28 July 1999. CA, USA.

Goldratt, E. M. (1986). The theory of constraints, New York: North River Press, Inc.

Gomez, C. P. (2002). A Study of the Situated Practice of Benchmarking in the UK Construction Industry. Unpublished Thesis. Birmingham: University of Birmingham, UK.

Hearn, S. \& White, N. (2009). Communities of practice: Linking knowledge, policy and practice. London, UK: Overseas Development Institute.

Jensen, P.A. (2006). Continuous briefing and user participation in buildingprojects.In:Adaptables 2006, International Conference on Adaptability in Design and Construction. Eindhoven University of Technology, Eindhoven, Netherlands.

Kiviniemi A. (2005).Requirements Management Interface to Building Product Models. Ph.D. thesis, Stanford University, Available at<http://cife.stanford.edu/online.publications/TR161> [Accessed 3rd March 2015]

Kotonya, G. \& Sommerville, I. (1998). Requirements engineering: processes and techniques.Chichester: John Wiley \& Sons.

Lave, J. \& Wenger, E. (1991). Situated Learning: Legitimate Peripheral Participation. Cambridge: Cambridge University Press.

Lawrence, B. (1997). Unresolved ambiguity. American Programmer, 5(5), pp.17-22.

Matthews, O. \& Howell, G. A. (2005). Integrated project delivery: an example of relationalcontracting. Lean Construction Journal, 2(1), pp. $46-61$.

McDermott, R., Wenger, E. \& Snyder, W. (2002). A guide to managing knowledge. Cultivating Communities of Practice. Boston, Massachusetts: Harvard Business School Press.

McKim, R., Hegazy, T. \& Attalla, M. (2000). Project performance control in reconstruction projects. Construction Engineering and Management, 126(2), pp. 137-141.

Möttönen, M., Härkönen, J., Belt, P., Haapasalo, H., \& Similä, J. (2009). Managerial view ondesign for manufacturing. Industrial Management \& Data Systems, 109(6), pp. 859-872.

Raji, A. U. \& Gomez, C. P. (2014). Influential factors that lead to spatial design modification of terrace house concepts. In: Proceedings of International Real Estate Research Symposium (IRERS).Kuala Lumpur, 29-30April 2014. Kuala Lumpur, Malaysia.

Reifi, M. H. \& Emmitt, S. (2011). Lean design management : exploring perception and practice. In: Otter, A., and Achammer, C., eds. Architectural Management in the Digital Arena, Proceedings of CIB W096, 2011. Eindhoven, The Netherlands: Eindhoven University Press.

Rooke, J. A., Sapountzis, S.,Koskela, L. J., Codinhoto, R. \& Kagioglou, M. (2010). Lean knowledge management: the problem of value. In:Proceedings of the 18th Annual Conference of the International Group for Lean Construction. Haifa, 14-16 July 2010. Haifa, Israel.

Sapountzis, S., Harris, K. \& Kagioglou, M. (2008a). The need for Benefits Realisation - Creating a benefits driven culture in UK's Healthcare Sector. In:1st HACIRIC Symposium - Redefining healthcare infrastructure. Integrating services, technologies and the built environment. London, 3-4 April 2008. London, UK.

Sapountzis, S., Harris, K. \& Kagioglou, M. (2008b). The development of a Benefits Realisation Management Process to drive successful programmes and projects,In: J. P. Pantouvakis (Ed.) Proceedings of the Joint Fourth Scientific Conference on Project Management (PM-04) \& the First IPMA /mednet Conference - Project Management Advances, Training \& Certification in the Mediterranean. Chios, 29-31 May 2008. Chios, Greece.

Tillmann, P., Tzortzopoulos, P. \& Formoso, C. (2010). Analysing benefits realisation from a theoretical perspective and its contribution to value generation. In: Proceedings of the 18th Annual Conference of the International Group for Lean Construction. Haifa, 14-16 July 2010. Haifa, Israel.

Tommelein, I.D., Riley, D. \& Howell, G.A. (1999). Parade game: impact of work flow variabilityon trade performance. Journal of Construction Engineering and Management, ASCE, 125(5),pp. 304-10.

Van der Voordt, T. J. M. \& van Wegen, H. B. R. (2005). Architecture in Use - An Introduction to the Programming, Design and Evaluation of Buildings. Oxford: Architectural Press.

Wiegers, K. E. (2003). Software requirements: practical techniques for gathering and managing requirements throughout the product development cycle. Washington DC:Microsoft Press. 